\title{
Reading Hypertext as Cyborg: The Case of Patchwork Girl
}

\author{
Jaya Sarkar \\ Ph.D. Scholar, Department of Humanities E Social Sciences, BITS Pilani (Hyderabad \\ Campus).ORCID: oooo-ooo1-6851-6976.Email: jayaısarkar@gmail.com
}

\begin{abstract}
This essay examines Patchwork Girl by Shelley Jackson to reveal how hypertext functions like the posthuman concept of the cyborg defined by Haraway as "a condensed image of bothimagination and material reality." For the theoretical framework, I draw on Katherine Hayles and Rosi Braidotti's theories of Posthumanism and cyborg subjectivity, among other Postmodernist Feminist ideas of the body and visual culture. Using these theories, my essay will answer the central question that underlies how this new revisionist and interactive medium of storytelling parodies the traditional roles of the author and the reader. Interpreting a 'cyborg' hypertext requires a "cyborg reader," not only because the reader shares a posthuman connection with the narrative in terms of involving their gestures through touch and click, but also because the hypertext forces the reader to adopt a gaze that is equally modular and fragmentary. My paper argues that just like the medium of hypertext itself, the author and the reader become a part of the cyborg subjectivity.
\end{abstract}

Keywords: Posthumanism, Cyborg, Hypertext, Haraway, Patchwork Girl, Frankenstein.

\section{Aesthetics of Patchwork Girl}

The term "cyborg", from its theoretical conception by Donna Haraway in "A Cyborg Manifesto" (1991), was conceived as an 'illegitimate offspring', a mutating transformative agency that inaugurated a different social subject in the contemporary age: "The cyborg is a condensed image of bothimagination and material reality, the two joined centers structuring any possibility of historical transformation"(Haraway, 1991, p. 7). This transformative agency attributed to the cyborg to replace the 'worker' of Socialism and the 'woman' of Feminism, underwent a thorough transmutation with the advent of new media post-9os. The 'cyborg' relocated from the sociopolitical realm to that of techno-materiality. Following Haraway's argument that a cyborg resists categorization as either technological or natural, then the form of hypertext through erasing the boundaries of print and technology becomes a cyborg.

In his 1965 article "A File Structure for the Complex, the Changing, and the Indeterminant," Ted Nelson introduced the term 'hypertext'-

Let me introduce the word 'hypertext' to mean a body of written or pictorial material interconnected in such a complex way that it could not conveniently be presented or represented on paper.(Nelson, 1965, p. 96)

(C) AesthetixMS 2020. This Open Access article is published under a Creative Commons Attribution Non-Commercial 4.o International License (http://creativecommons.org/licenses/by-nc/4.o/), which permits non-commercial re-use, distribution, and reproduction in any medium, provided the original work is properly cited. For citation use the DOI. For commercial re-use, please contact editor@rupkatha.com. 
Hypertexts permit reading texts with advanced features like "enhanced functionality, customized views and improved knowledge synthesis and representation." Given the multiple choices in the narrative, the readers get a God-like power to control the narrative that the author is writing. Hypertext extends Robert Brooke's postmodern critique across another dimension: not only must the author be out of control of his or her creative processes, but the author can no longer control the way the reader navigate through the text, or even the order of the contents of the text itself. Michael Joyce's hypertext fiction afternoon, a story, (1994), one of the first hypertexts, resembled the fluctuations and the non-linear nature of this readability of the hypertext, which makes it different from the traditional texts in print.Even a few books in print like Julio Cortázar's Hopscotch (1963) has a hypertextual format of 56 regular chapters and 99 "expendable" ones. Unlike traditional fiction reader, the hypertext reader is not required to read the story from beginningto end. There is no real ending, no sense of actual closure.

Patchwork Girl centers on the story of the female monster who succeeds in escaping to the New World and survives for 175 years. In the Introductory paragraph of Frankenstein, or, The Modern Prometheus: The 1818 Text, Mary Shelley referred to her creation by using a phrase from the Bible: "And now once again, I bid my hideous progeny to go forth and prosper" (Shelley, 2018, p. 10). With this phrase, Shelley turned from an author to the progenitor of the monster; her novel. It is the contradiction within the Biblical metaphor "hideous progeny" that acts as a source of inspiration for the contemporary writer Shelley Jackson to produce a new potentially 'monstrous' version of literature called the 'hypertext.' In Patchwork Girl, Victor Frankenstein'saborted second creation, the female monster, whom he violently tears up midconstruction, is sewn up by the author Mary Shelley herself and then she engages in a love affair with her creation, before the monster sets out for America to start her own life. The monster is thus, "a cyborg who is queer, dis-proportioned, and visibly scarred." This definition of 'cyborg' is developed in my essay by looking at how the medium of hypertext behaves in this way and the readers by trying to construct this cyborg are giving birth to a structure "without gender, which is perhaps a world without genesis, but maybe also a world without end"(Haraway, 1991, p. 7).

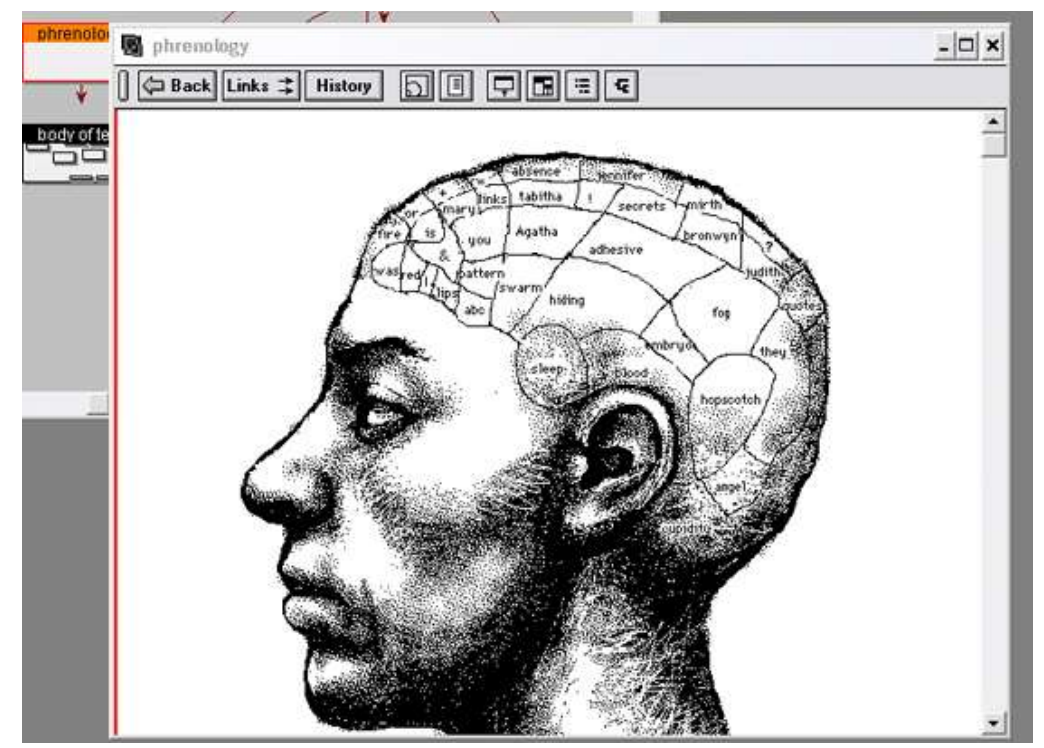

Figure 1: "Phrenology" lexia from Patchwork Girl. 1995.Eastgate Systems 
The title-page represents clearly that this is a collaborative work of fiction by Mary Shelley and Shelley Jackson: "Mary/Shelley and herself". When the monster calls herself a "mixed metaphor", she is not only drawing our attention to her hybridity (both biological and hypertextual) but also all the "borrowed parts, annexed territories" which, like Frankenstein's creation, survives on their own. By producing this conceptual space, another cyborg in the form of the 'hypertext,' is erected. Among the most striking examples of the merging of fiction and metafiction and the foregrounding of the act of construction of the text, paralleled by the creation of the monster's body, is the "phrenology" lexia. It represents a graphic drawing of the profile of a human head (see Fig.1), whose scalp is partitioned into numerous sections, each of which contains a name or phrase, that function as links and entryways to several lexias gathered under the subheading "body of text," which highlights the multiplicity of the human body and the multiplicity of hypertext. This interconnection and complex interplay between the human body and body of text are underlined by Jackson yet again in Stitch Bitch: "Boundaries of text are like boundaries of bodies, and both stand-in for the confusing and invisible boundary of the self."

Patchwork Girl consists of five main parts: "story," "graveyard," "journal," "crazy quilt" and "body of text," each of these are further divided into several sections, and the links intertwine them with the others. On the whole, this hypertext fiction consists of 323 lexias, which are joined by over 400 links. Each section leads down a trail that takes the story in numerous ways through different connecting words and pictures. Where the work begins is left to the reader to choose. The postmodern view on the text, characterized by intertextuality, nonlinearity, fragmentation, dispersal, and dissemination, is treated with irony in the patchwork of a wide range of texts. The four different maps help structure the narrative and provide some orientation to the reader. But no matter how many times we reassemble the lexias, they will disintegrate, and the process of creation has to begin anew. Jackson's female monster departs from the systematic treatment of cyborgs in fiction concerning their corporeality. In various ways, this cyberfiction foregrounds the materiality of the non-normative body. The monster is as much a biological organism as an artificial construct- a posthuman being. The two essential manifestations of the creative act: the creation of a human's life and artistic creation are expressed through the metaphors of the traditionally female arts such as sewing, weaving, quilting. As Haraway observes, "myth and tool constitute each other," and communication technologies and biotechnologies are the most crucial tools recrafting our bodies (Haraway, 1991, pp. 205-206). Therefore, the monster is made "like a quilt," pieced together from multiple parts and become a cyborg- a hybrid, multi-layered metaphor for body and text.

When one launches the Storyspace software required to read Patchwork Girl, the first image that pops up on the screen is a drawing of the monster's patched-up body (see Fig.2), which stands for the discontinuous structure of the work itself. Such an image suggests the interruption of an idealistic and transcendental self-unity of a body and enables the sharing of a universe through an aesthetic of touch that places the body of the cyborg at the intersection between sense and matter. From the link labelled "a graveyard", the reader is led to an apparent epitaph for the patchwork girl that reads,

Here Lies a Head, Trunk, Arms (Right and Left), and Legs (Right and Left) as well as divers Organs appropriately Disposed. May they Rest in Piece. (Jackson, 1995)

Here the reader finds a list of several different parts of the patchwork girl's body; each body part is linked to a brief description of the part's previous owner. The readers may choose whatever order they wish to reconstruct the body, stitching the parts together differently with each reading. 


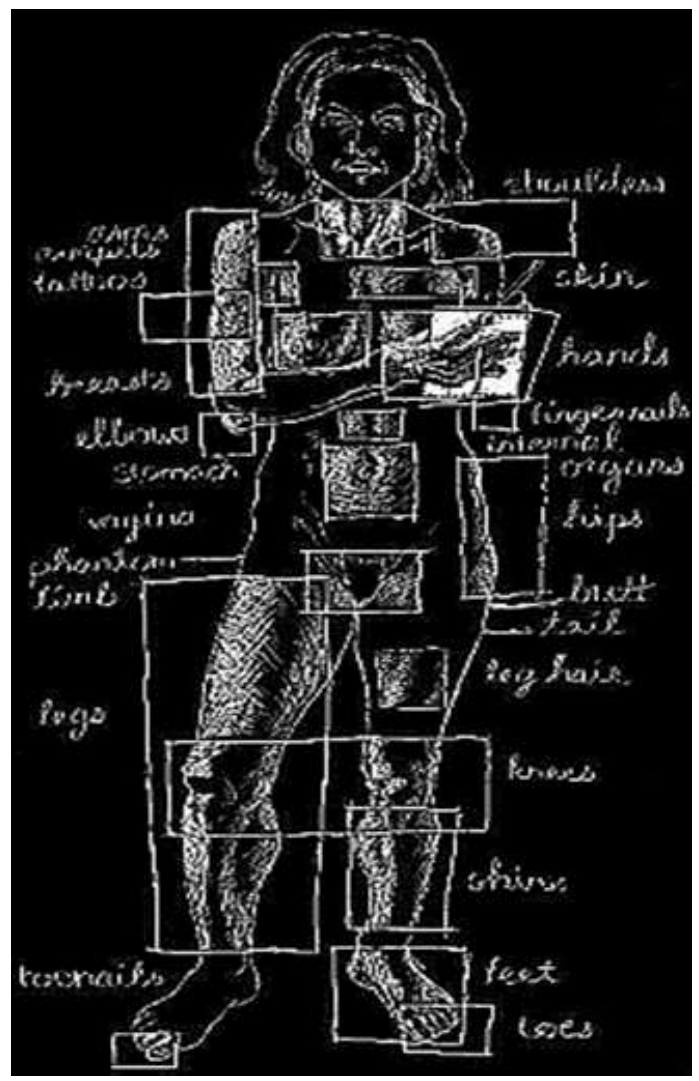

Figure 2: "my body" lexia: displayed before the section "graveyard"from Patchwork Girl. 1995.Eastgate Systems

The way the readers interact with Patchwork Girl is aesthetically grotesque from the opening graphic, in which we stitch the scars in the body of the Patchwork Girl in order to begin the process of reading. This example of the instability and multiplicity of the cyborg is a critical point in the story: when the monster starts to disintegrate, her body parts begin to fly in different directions. The dispersal and multiplying of identity are not seen as monstrous by Jackson but as an acceptable and even normalizing experience, as the very structure of hypertext. As Katherine Hayles states: "the text not only normalizes the subject-as-assemblage but also presents the subject-as-unity as a grotesque impossibility" (Hayles, 2000). The "graveyard" section in Patchwork Girl and most of the remaining text gives us an opportunity to consider how gothic as a genre serves to complicate the hypertext technology. The "graveyard" is the specific location within the hypertext from which other (textual) lives are resurrected(see Fig.3). When the reader clicks on the various body parts and finds the description of the people whose parts are used to construct the body of the monster, we are automatically drawn to the gothic nature of the hypertext- one that signifies the ghostly presence of the corporeal, similar to Derrida's Cinders. Here the reader resurrects not only the cyborg creature but also Mary Shelley's original text. The overall activity of reading this hypertext and to explore "the banished body" haunts not only the eighteenth-century rational intellect but also the posthuman transcendence (Keep, 2006, p. 41). 


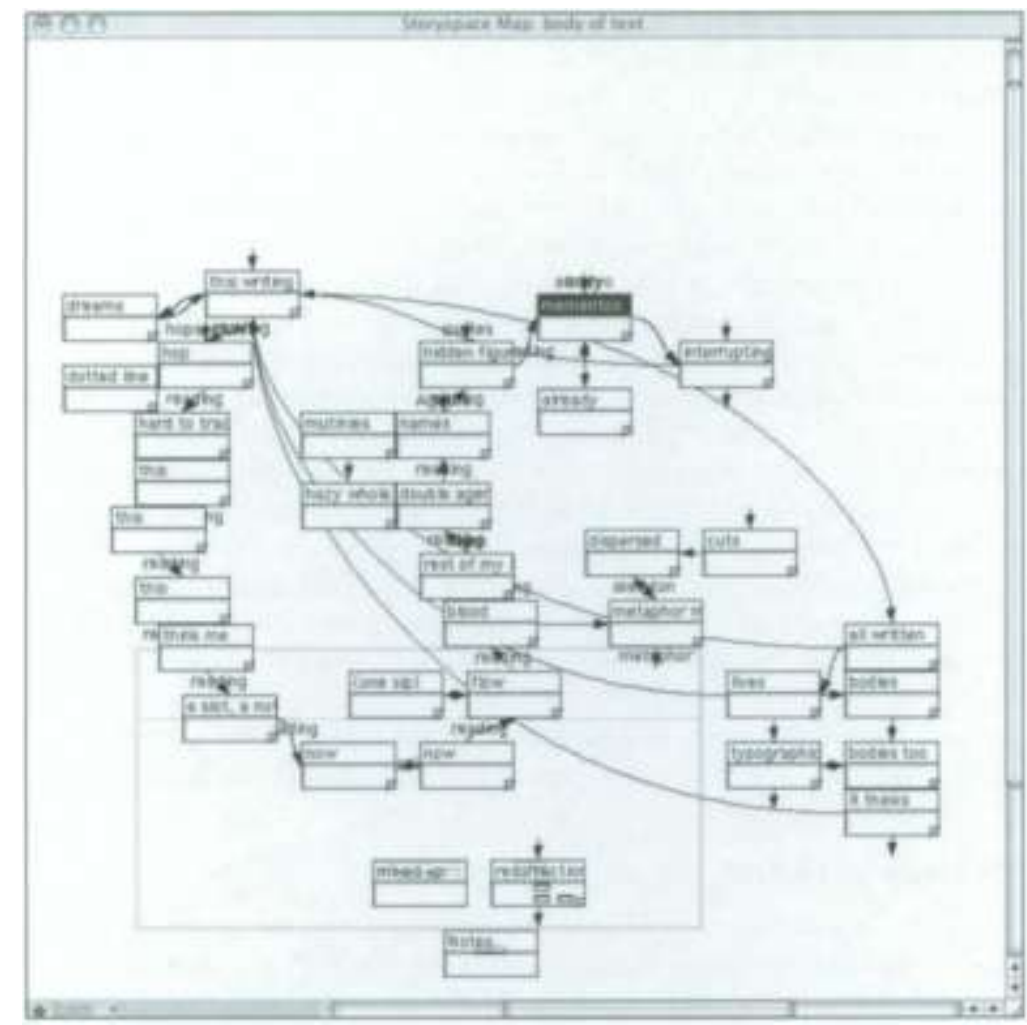

Figure 3: "body of text" lexia from Patchwork Girl. 1995.Eastgate Systems

\section{Cyborg Subjectivity}

In a manner reminiscent of Derrida, Shelley Jackson tries to converge the boundaries of the text with that of the body of the cyborg, and in the process, highlights how our language constructs our identities. As a result, Jackson concludes: "I am a mixed metaphor." (Jackson, 1995), or an extended comparison of myself. When in Shelley Jackson's narrative, Mary Shelley brings her monster to life and assembles her by "stitching deep into the night by candlelight", the inherent connection between writing and patching is discussed in detail in two almost similar lexias ("written" and "sewn") which are required to be read parallelly. When the readers of the hypertext shape up the scattered chunks of text into a lucid form, they also bring to life the hidden hyperlinks that modify or interrupt the textual body. The Storyspace software provides a facility to the readers to save their respective path of links that have constituted their individual readings, and also to add margin notes in each lexias. The readers thus, becomes a part of the body of the text, by stitching their writings to the narrative quilt.

Readers of Patchwork Girl encounter a type of cyborg subjectivity themselves since they are intertwined with the technology that controls the story's creation; they sew their own monster and their own monstrous text while recognizing that their desire to interact with the monster spurs their choices and decides their links.As the control shifts from the author to the reader, the author/reader becomes a cyborg, "both materially and intellectually" (Johnson-Eilola, 1993, p. 383). The technology, therefore, mingles the actions of the machine with "the subjectivity we attribute to characters, authors, and ourselves as readers" (Hayles, 2000, p. 51) The monster not only destabilizes what counts as natural through this multiplicity, but she also destabilizes the postmodern fantasy that everything is open to textualization. She challenges definitions of 
monstrosity by continually referring to the state of her fragmented and reassembled body, expressed through the structure of the hypertext that is itself neither unified nor autonomous. The role the technologically mediating apparatus of the Storyspace software plays in this figuration is central: Patchwork Girl is in every sense a work of hyperfiction, as it self-reflexively deploys the possibilities that the medium allows, while simultaneously allowing the reader great freedom and control to shape the narrative. Reading Patchwork Girl, appeals to the cyborgian power and turns the readers into a kind of Dr. Frankenstein for patching together the different pieces of the textual corpus, and thus creating our own monstrous, patched-up reading.

The qualities of collage in George Landow's view are so fundamental to hypertext, "particularly those of appropriation, assemblage, concatenation, and the blurring of limits, edges, and borders- characterize a good deal of the way we conceive of gender and identity" (Landow, 2006, p. 3). By truly 'sewing' her very own words into the entry, Jackson exhibits the real creation of a composed patched unique blanket. She sees that hyperspace is the perfect condition for écriture féminine or female composition, which might be viewed as one of Jackson's key messages. Patchwork Girl contributes to this portrayal of a new feminist alternative with its use of technology, its portrayal of a female monster that is endowed with agency and accountability, the manner in which Shelley Jackson addresses Mary Shelly as her fictional mother, its openendedness, and its deconstruction of female subjectivity and monstrosity. In Haraway's line of thought, the hypertext technology makes it possible to reconstruct our identity, sexuality, and even gender. The feminine associations with patching serve to mark Jackson's hypertext a feminist production. Patchwork Girl in the form of a collage assembles Shelley Jackson's (and Mary Shelley's and Victor Frankenstein's) female cyborg, forming a hypertext "Everywoman" who embodies assemblage, concatenation, juxtapositions and blurred, recreated identities - one of the many digital fulfilments of the twentieth-century.

Patchwork Girl is acyborg in a hybrid theoretical sense of Barthes and Haraway, a posthuman technological creation of the mediating apparatus of the interactive software. This hypertext stages an inquiry into processes of materialization to challenge the effective terms in which the relations between the social and the natural, cognition, and the physical body, meaning, and the medium is understood. The readers of Patchwork Girl attempt to construct a cyborg text and in the process become a part of the cyborg subjectivity. The popularity of such interactive software like Storyspace and other immersive reading applications like Chapters: Interactive Stories and Choices: Stories You Play make hypertexts an important genre of the Posthumanist literature. In visual culture, interactive movies like Bandersnatch make a new form of narrative based on interactivity, where the boundaries between what is real and what is unreal, is contested. Such interactive narratives consider the possible technologies and advancements to make interpretation, communication, reading, and composing advanced, both in terms of creativity and intellect. In Rosi Braidotti's words, "the question of what it means to be human is taking a new turn," with the constant use of new technology, which results in the boundaries between the human and the non-human realms to become increasingly blurred. 


\section{References}

Braidotti, R. (2017). The Posthuman. Cambridge: Polity Press.

Brooke, R. (1989). Control in Writing: Flower, Derrida, and Images of the Writer. College English, 51(4), 40517.doi:10.2307/377529

Carazo, C., \& Jiménez, M. (2006). Gathering the Limbs of the Text in Shelley Jackson's 'Patchwork Girl.' Atlantis, 28(1), 115-129. JSTOR. Retrieved May 31, 2020, from http://www.jstor.org/stable/41055233

Derrida, J. (1981). Dissemination. (B. Johnson, Trans.). Chicago: Chicago UP. (1972)

Derrida, J. (1987). Cinders. Lincoln: University of Nebraska Press.

Haraway, D. (1991). A Cyborg Manifesto: Science, Technology, and Socialist-Feminism in the Late Twentieth Century. In I. Szeman \& T. Kaposy (Eds.),Simians, Cyborgs and Women: The Reinvention of Nature (pp. 149-181).London: Routledge.

Haraway, D. (1995). Cyborgs and Symbionts: Living Together in the New World Order. In C.H. Gray, S. Mentor \& H. Figueroa-Sarriera (Eds.),The Cyborg Handbook (pp. xi-xix). London: Routledge.

Hayles, N.K. (1999). How We Became Posthuman: Virtual Bodies in Cybernetics, Literature, and Informatics. Chicago: Chicago UP.

Hayles, N.K. (2000). Flickering Connectivities in Shelley Jackson's Patchwork Girl: The Importance of Media-Specific Analysis. Postmodern Culture, 10(2). doi:10.1353/pmc.2000.0011

Jackson, S. (1995).Patchwork Girl; or, a Modern Monster. Eastgate Systems.

Jackson, S. (1998). Stitch Bitch: The Patchwork Girl.Transformations of the Book Conference. Cambridge: MIT.

Johnson-Eilola, J. (1993). Control and the Cyborg: Writing and Being Written in Hypertext. Journal of Advanced Composition, 13(2), 381-399.JSTOR. Retrieved May 31, 2020, from http://www.jstor.org/stable/20865923

Keep, C. (2006). Growing Intimate with Monsters: Shelley Jackson's Patchwork Girl and the Gothic Nature of Hypertext.Romanticism on the Net, 41-42. https://doi.org/10.7202/013156ar

Landow, G.P. (2006).Hypertext 3.o: Critical Theory and New Media in an Era of Globalization. Maryland: John Hopkins UP.

Mitchell, D.T., \& Snyder, S.L. (200o). Narrative Prosthesis: Disability and the Dependencies of Discourse. Michigan: University of Michigan Press.

Nelson, T. H. (1965). Complex Information Processing: A File Structure for The Complex, The Changing and the Indeterminate. Proceedings of the 1965 2oth National Conference.

Regnauld, A. (2009). Interrupting D: 'Patchwork Girl's' Syncopated Body. Revue Française D'études Américaines, (121), 72-83.JSTOR. Retrieved May 31, 2020. http://www.jstor.org/stable/20875901

Shelley, M.W. (2018).Frankenstein, or, The Modern Prometheus: The 1818 Text. (3rd ed.). Oxford: Oxford UP.

Jaya Sarkar is pursuing her PhD. in Cultural Studies at BITS Pilani- Hyderabad Campus, India. Her proposed thesisexamines the aesthetics of the posthumanist and disabled bodies, posthumanist literature, and interactive applications. Her research areas include Posthumanism, Postmodernism, Feminist Studies, Digital Humanities, Social Media Studies and Disability Studies. She has edited a book titledIndustrial Melanism: An Evolutionary Reverse Swing which was published in April, 2019. 